pag

Business School

WORKING PAPER SERIES

Working Paper 2014-300
The environmental Kuznets curve and sustainability: A panel data analysis

Sahbi Farhani

Sana Mrizak

Anissa Chaibi

Christophe Rault

http://www.ipag.fr/fr/accueil/la-recherche/publications-WP.html

IPAG Business School

184, Boulevard Saint-Germain

75006 Paris

France 


\title{
The environmental Kuznets curve and sustainability: A panel data analysis
}

\author{
Sahbi Farhani \\ LAMIDED, ISG Sousse, University of Sousse, 4000 Sousse, Tunisia \\ Email: sahbi.farhani@ipag.fr \\ Sana Mrizak \\ RECITS-IRTES, University of Technology of Belfort-Montbéliard, France \\ Email: sana.mrizak@utbm.fr \\ Anissa Chaibi \\ IPAG Lab, IPAG Business School, Paris, France \\ Email: anissa.chaibi@ipag.fr \\ Christophe Rault \\ Toulouse Business School, France \\ Email:chrault@hotmail.com
}

\begin{abstract}
In recent years, sustainability has represented one of the most important policy goals explored in the environmental Kuznets curve (EKC) literature. But related hypotheses, performance measures and results continue to present a challenge. The present paper contributes to this ongoing literature by studying two different EKC specifications for 10 Middle East and North African (MENA) countries over the period 1990-2010 using panel data methods. For the first specification, namely EKC, we show that there is an inverted Ushape relationship between environmental degradation and income; while for the second specification, namely modified EKC (MEKC), we show that there is an inverted U-shape relationship between sustainability and human development (HD). The relationships are shaped by other factors such as energy, trade, manufacture added value and the role of law. More interestingly, findings from the estimation show that $\mathrm{EKC}$ hypothesis, HD and sustainability are crucial to build effective environmental policies.
\end{abstract}

Keywords: Environmental Kuznets Curve; Sustainability; Panel data analysis. 


\section{Introduction}

Understanding environmental degradation and its determinants has become increasingly important in recent years. Within the environmental Kuznets curve (EKC) framework, pioneering contributions stressed the importance of pure economic growth as a major source of environmental degradation (Shafik, 1994; Grossman and Krueger, 1995; Kijima et al., 2010). Recently, other contributions have shown the important role played by further aspects related to globalization (Tisdell, 2001), to education and inequality (Hill and Magnani, 2002), to human capital, technology advancement, industry structure and urbanization (Jun et al., 2011), to poverty (Liu, 2012), to energy consumption (Ang, 2007; Apergis and Payne, 2009, 2010; Lean and Smyth, 2010; Arouri et al., 2012), or both to energy consumption and trade (Ang, 2009; Halicioglu, 2009; Jalil and Mahmud, 2009; Jayanthakumaran et al., 2012; Farhani et al., 2014a, b).

Moreover, a considerable attention has been paid to the vital role of sustainability in the environmental improvement. In particular, human development (HD) has been seen as a one of major economic growth's driving forces (Ranis et al., 2000; Suri et al., 2011). Some studies such as Costantini and Monni (2008) and Costantini and Martini (2010) have introduced HD as a factor of sustainable development in the EKC approach. The findings suggest that the EKC model is deeply influenced by HD dimensions. Furthermore, the role of sustainability is a necessary additional perspective that should be scrutinized and strictly connected to the quality of institutions and investments for the improvement of development. Besides, an approach using theoretical and empirical investigations of the EKC to relate the development degree to the capacity of the curve is presented in order to describe sustainability (Stern et al., 1996; Tisdell, 2001; Hartman and Kwon, 2005). At this purpose, some contributions have attempted to investigate the theoretical implications of sustainability and the possible linkages with the empirical EKC formulation. The role of sustainability (and not only environmental degradation), the implications related to technical progress, and the statistical techniques based on panel data (and not pure cross-section analyses) represent the main steps ahead recently made by the scientific community.

Despite the huge diffusion of EKC studies, this approach has been criticized for incompleteness in the sustainable development context. Our article contributes to the recent literature and proposes i) to modify the standard EKC by changing the dependent variable substituting a pure environmental stress as in the standard EKC with a wider assessment of environmental pressure proxied the environmental degradation index (Babu and Datta, 2013); ii) to use simultaneous models in order to study $\mathrm{EKC}$ by incorporating resource curse hypothesis (RCH) (Costantini and Monni, 2008), and iii) to study a modified EKC (MEKC) including well-being aspects and sustainability of the development process (Costantini and Martini, 2010). Precisely, we propose to replace the independent income variable in the original EKC model (i.e., gross domestic product "GDP") with HD Index (HDI) and to also replace emissions with a measure of macroeconomic sustainability such as the Genuine Saving (GS) index ${ }^{1}$ (Neumayer, 2004; Costantini and Monni, 2008; Costantini and Martini, 2010). All our models are estimated using panel data methods in order to control the heterogeneity and the colinearity among the variables (Baltagi, 2005).

\footnotetext{
${ }^{1}$ Genuine saving index, (also known as Adjusted net saving), is a sustainability indicator building on the concepts of green national accounts. Genuine saving index measures the true rate of savings in an economy after taking into account investments in human capital, depletion of natural resources and damage caused by pollution (World Bank, 2010).
} 
Empirically, we use recent datasets (from 1990 to 2010) to investigate the issues for 10 Middle East and North African (MENA) countries. The dimensions of the panel data set are chosen to include as many countries as possible each with a reasonable time length of observations. Furthermore, the main reason to consider the MENA region is due to the fact that the World Bank, through its Global Monitoring Report 2008, claims that "a number of countries in the region remain on an unsustainable path, consuming profits on natural resource exploitation rather than investing these profits to ensure long-term economic sustainability". In addition, the same report asserted that "the Middle East \& North Africa region has increased its carbon dioxide emissions, faces diminishing critical per capita water resources, and is at risk on several fronts from climate variability". 2 This claim confirms the general subject of the present study and may also help us to choose the more relevant variables to include in our analysis.

Methodologically, our study uses the most developed cointegration test suggested by Pedroni $(1999,2004)$ to check for the presence of two long-run equilibrium relationships. In the first one, we have taken per capita real GDP, energy consumption, trade openness, manufacture value added and modified HDI (MHDI) as explanatory variables in the EKC model $\left(\mathrm{CO}_{2}\right.$ emission is a dependent variable); while in the second long-run relationship, we have taken HDI, energy consumption, trade openness, manufacture value added and the rule of law (RL) as explanatory variables in the MEKC (negative $\mathrm{GS}^{3}, \mathrm{GS}^{-}$, as a dependent variable). In the next step, we have estimated the two models based on two recent techniques namely panel fully modified ordinary least squares (FMOLS, initially suggested by Phillips and Hansen, 1990) and dynamic OLS (DOLS, initially suggested by Saikkonen, 1991; and Stock and Watson, 1993). According to the works by Phillips and Moon (1999), Kao and Chiang (2001), Pedroni (2001a,b) and Mark and Sul (2003), these techniques produce asymptotically unbiased and normally distributed estimators ${ }^{4}$. Finally, Granger causality test based on the panel vector error correction model (VECM) is used to verify the direction of causality among the variables of interest.

The remainder of this paper is organized as follows. Section 2 presents the data and models specification. Section 3 introduces our econometric methodology. Section 4 discusses our empirical results. Section 5 concludes and provides policy implications from our findings.

\section{Data and models specification}

\subsection{Data}

The data set is a balanced panel of 10 MENA countries over the annual period 1990-2010. The selected MENA countries included in the sample are: Algeria (ALG), Bahrain (BHR), Egypt (EGY), Iran (IRN), Jordan (JOR), Morocco (MRC), Oman (OMN), Saudi Arabia (SAU), Syria (SYR), and Tunisia (TUN). These variables are obtained from World Bank Development Indicators (WDI, CD-ROM).

To meet that need to consider development process rather than pure economic growth, we believe it is necessary to investigate both EKC and MEKC models by including well-being aspects and sustainability.

\footnotetext{
${ }^{2}$ This claim has also been mentioned in Arouri et al. (2012).

${ }^{3}$ The use of $\mathrm{GS}^{-}$is caused by the unsustainable development of MENA region.

${ }^{4}$ The use of FMOLS and DOLS estimators is also due to the fact that although OLS estimators are superconvergent, their asymptotic distribution is biased and depends on the nuisance parameters (Pedroni, 2004).
} 
The models specification that will be adopted in the next sub-section, allowing the interrelationship of $\mathrm{EKC}$ and $\mathrm{MEKC}$, is incorporated to include the following variables:

i) $E K C$ : $\mathrm{CO}_{2}$ emissions $(C)$ is measured in metric tons per capita; Output $(Y)$ is measured using per capita real GDP in constant 2000 US\$; and MHDI as a proxy for HDI is represented as the sum of the initial level of life expectancy and secondary education as a proxy for the initial level of human capital, but without including income (GDP, $Y$ ) in order to avoid the multicollinearity between $M H D I$ and $Y$.

ii) $M E K C$ : Negative GS per capita $(G S)$ in constant 2000 US\$; HDI is represented as the MHDI (i.e., life expectancy and education) but with including income $(Y)$; and rule of law $(R L)$ as a one of important dimensions of governance in the control of corruption.

iii) $E K C$ and $M E K C$ : Energy consumption $(E)$ is measured using energy use in $\mathrm{kg}$ of oil equivalent per capita; Trade openness $(T)$ is measured in \% of GDP; and Manufacture value added $(M A N)$ is measured in \% of GDP.

\subsection{Models specification}

In the last decade, the question of omitted variable bias in the relationship between emissions and income is also subject to the issue of the EKC hypothesis. At this level, Ang (2007), Apergis and Payne (2009, 2010), Lean and Smyth (2010) and Arouri et al. (2012) introduced energy consumption into the relationship between emissions and income as a mean to circumvent omitted variable bias. The inclusion of energy consumption appears to be relevant in light of the growing literature on the causal relationship between these variables.

In this approach, the long-run relationship between emissions $(C)$, income $(Y)$ and energy consumption $(E)$ is given by the following equation:

$$
C=\alpha_{0}+\alpha_{1} Y+\alpha_{2} Y^{2}+\alpha_{3} E+\varepsilon
$$

Furthermore, Antweiler et al. (2001), Cole and Elliott (2003), and Ang (2009) have argued that it is possible to also include trade. Hence, they indicated that the effect of trade on the environment depends on the relative empirical issue. With respect to this methodology, Halicioglu (2009), Jalil and Mahmud (2009), Jayanthakumaran et al. (2012), and Farhani et al. (2014a, b) also suggested the impact of trade on the emissions-income-energy nexus. This method can also be considered as a solution for the problem of omitted variable bias in the econometric estimation. With respect to this methodology, the quadratic EKC equation used to examine the relationship between emissions $(\mathrm{C})$, income (Y), energy consumption (E), and trade $(\mathrm{T})$ is given by the following equation:

$$
C=\alpha_{0}+\alpha_{1} Y+\alpha_{2} Y^{2}+\alpha_{3} E+\alpha_{4} T+\varepsilon
$$

In a similar way, other works have shown that the inclusion of control variables in the EKC equation may improve the representation of the effects linked to trade and the manufacturing sector (Hettige et al., 2000; Tisdell, 2001; Cole, 2004) or linked to well-being aspects such as income distribution, education, health and more generally human development (Magnani, 2000; Gangadharan and Valenzuela, 2001; Hill and Magnani, 2002), democracy, corruption and other institutional aspects (Lopez and Mitra, 2000; Dasgupta et al., 2006; Farzin and Bond, 2006). Following this way, Costantini and Monni (2008) proposed the functional form of the EKC model: 


$$
\underline{E K C .} \quad C=\alpha_{0}+\alpha_{1} Y+\alpha_{2} Y^{2}+\alpha_{3} T+\alpha_{4} M A N+\alpha_{5} H D I+\varepsilon
$$

The inverted U-shaped relation between pollutant emissions $(C)$ and GDP $(Y)$ depicted in the EKC of Eq. (3) can be reformulated by using MHDI, with replacing HDI by MHDI that does not include the income factor, i.e. GDP. Furthermore, the absence of the GDP index in the MHDI can avoid the multicollinearity between $Y$ and $M H D I$. Thus, our model will be based on the term of MHDI.

Rather than adding explanatory variables, Jha and Murthy (2003) and Abou-Ali and Abdelfattah (2013) attempt to build a MEKC model using HDI as an explanatory variable of polluting emissions, confirming an inverted U-shaped curve even with a broad notion of development. Many main arguments have been proposed to change the EKC by the MEKC. On the demand side, there is the role of public opinion in requiring policy actions to reduce environmental degradation where environment is no more a luxury good, as it is in poor economies. On the supply side, there is the role of structural changes in the economic system where economic growth is followed by technological innovation and change in the productive structure (from basic industries to high-tech services) producing a reduction in polluting emissions. The specific nature of the abatement technologies with increasing returns to scale could constitute a further explanation of the EKC where high fixed initial investment costs for pollution abating techniques reduce the capacity of poor countries to implement pollution control policies (Andreoni and Levinson, 2001). Many contributions have empirically tested the existence of an EKC hypothesis using cross-country relationships (Shafik, 1994; Grossman and Krueger, 1995; Stern et al., 1996) or using time series analysis (Vincent, 1997; Egli, 2002). Finally, many contributions try to shed some light on possible failures in the theoretical interpretation of the EKC (Arrow et al., 1996; Munasinghe, 1999; Stern and Common, 2001).

In this context, we attempt to substitute the income factor of the EKC, i.e. GDP, with a more capability-oriented measure, i.e. HDI, in order to maintain other control variables such as the percentage of polluting industries in the whole economy or the effect of HD on pollution. Furthermore, in order to represent a more general framework geared towards sustainable development, the pollution-related dependent variable is replaced by a macroeconomic sustainable indicator, i.e. GS. The GS index provided by Costantini and Monni (2008) is formally expressed in Eq. (4):

$$
G S=\dot{K}-\left(F_{R}-f_{R}\right)(R-g)-b(e-d)
$$

where $\dot{K}$ represents economic capital formation while other terms are adjustments for consumption and degradation of natural capital (Hamilton, 2000). In particular, the economic value of natural resources consumption (resources extracted " $R$ " minus natural growth rate " $g$ " for renewables) is given by the resource rental rate $\left(F_{R}\right)$ net of the marginal cost of extraction $\left(f_{R}\right)$, while pollution (emissions " $e$ " minus natural dissipation rate " $d$ ") is evaluated by the marginal cost of abatement " $b$ ".

GS is based on the assumption of perfect resource substitutability and it could therefore be interpreted as a limit value of sustainability, where:

GS $>0 \rightarrow$ Sustainability $\left(\mathrm{GS}^{+}\right)$

GS $=0 \rightarrow$ Minimum level of sustainability

GS $<0 \rightarrow$ Non-sustainability $\left(\mathrm{GS}^{-}\right)$ 
At this level, the relation between pollutant emissions $(C)$ and GDP $(Y)$ presented in the EKC can be reformulated by using a MEKC. It consists to replace the dependent variable (pollution emissions, $C$ ) by $\mathrm{GS}^{-}$as a measure of non-sustainability, and to replace also GDP $(Y)$ by HDI. This simple accounting rule allows the original EKC, but with replacing the dependent variable by a negative effect of GS related to the situation of unsustainable development of the MENA region. Furthermore, Costantini and Monni (2008) suggested that the use of HD measure (and not a simple economic growth level) can allow broader considerations to be made on the sustainability of the development path, if future generations could enjoy the same well-being level (and not only income). In addition, concerning the value added of such analysis is the presence of depletion and degradation value of natural resources contained in the GS index compared with the simple pollutant emissions considered in a classical EKC model (Costantini and Martini, 2010). This indicates that manufacture value added $(M A N)$ may play a vital role in the EKC approach.

In line with classic EKC, the inclusion of other control variables such as trade openness and the share of MAN even allows us to analyze the effects of HD on sustainable development. The aim of this methodology consists to compare the results of EKC and MEKC where relationships between economic development and pollution are synthesized. Empirically, Costantini and Monni (2008) proposed the following functional form of the MEKC:

$$
\underline{M E K C} . \quad G S^{-}=\beta_{0}+\beta_{1} H D I+\beta_{2} H D I^{2}+\beta_{3} T+\beta_{4} M A N+\beta_{5} R L+\mu
$$

In our specification, the main purpose of the present paper has been made to combine the approach of Halicioglu (2009), Jalil and Mahmud (2009), Jayanthakumaran et al. (2012), and and Farhani et al. (2014a, b) with the Costantini and Monni's (2008) approach.

In this context, our final functional forms representing the EKC and MEKC will be given by Eqs. (6-7):

$$
\begin{gathered}
\underline{E K C .} \quad C_{i, t}=\alpha_{0, i}+\alpha_{1, i} Y_{i, t}+\alpha_{2, i} Y_{i, t}^{2}+\alpha_{3, i} E_{i, t}+\alpha_{4, i} T_{i, t}+\alpha_{5, i} M A N_{i, t}+\alpha_{6, i} M H D I_{i, t}+\varepsilon_{i, t} \\
\underline{M E K C .} G S_{i, t}^{-}=\beta_{0, i}+\beta_{1, i} H D I_{i, t}+\beta_{2, i} H D I_{i, t}^{2}+\beta_{3, i} E_{i, t}+\beta_{4, i} T_{i, t}+\beta_{5, i} M A N_{i, t}+\beta_{6, i} R L_{i, t}+\mu_{i, t}
\end{gathered}
$$

where $i, t, \alpha_{0 i}, \beta_{0 i}$, and $\varepsilon$ and $\mu$ denote the country, the time, the fixed country effect and the white noise stochastic disturbance terms, respectively. The parameters $\alpha_{1 i}, \alpha_{2 i}, \alpha_{3 i}, \alpha_{4 i}, \alpha_{5 i}$ and $\alpha_{6 i}$ are the long-run elasticities of emissions with respect to income, squared income, energy consumption, trade, manufacture value added and MHDI, respectively. The parameters $\beta_{1 i}, \beta_{2 i}, \beta_{3 i}, \beta_{4 i}, \beta_{5 i}$ and $\beta_{6 i}$ are the long-run elasticities of GS with respect to HDI, squared HDI, energy consumption, trade, manufacture value added and rule of law, respectively.

As for expected signs in Eqs (6-7), the signs of $\alpha_{1 i}$ and $\beta_{1 i}$ are expected to be positive whereas a negative sign is expected for $\alpha_{2 i}$ and $\beta_{2 i}$. This is a necessary for the EKC hypothesis to be true. The sign of $\alpha_{3 i}$ and $\beta_{3 i}$ is expected to be positive because more energy consumption can increase the scale of an economy and stimulate emissions. The expected sign of $\alpha_{4 i}$ and $\beta_{4 i}$ is mixed depending on the level of economic development stage of a 
country. For the case of developed countries, this sign is expected to be negative as they cease to produce certain pollution intensive goods and begin to import these from other countries with less restrictive environmental protection laws. But for the case of developing countries, this sign expectation is reversed as they tend to have dirty industries with heavy share of pollutants (Grossman and Krueger, 1995). It also means that an increase in trade openness will increase pollution due to a comparative advantage in dirty production under weaker environmental regulations (Jayanthakumaran et al., 2012; Farhani et al., 2014a, b).

Concerning the signs of manufacture and HDI, the two conditioning variables are positively contributed to reaching a higher level of emissions. The presence of the two variables, MHDI and GS, in the MEKC allows integrating the causal relationship between economic grwoth and environmental degradation with HD dimensions and sustainability. In particular, the control of corruption expressed as RL is an engine for economic growth and sustainable development. In general, the analysis concerning corruption is intrinsically related with RL. The perspective that a weak RL implies a high level of corruption is supported since Leff (1964) and Huntington (1968). Nowadays, the World Bank considers RL to be one of important dimensions of governance in the control of corruption. In brief, the idea is that the countries with a high RL ensure that no one is above the law, and thus the corruption may decrease (Kaufman et al., 2003; de Mendonça and da Fonseca, 2012).

\section{Econometrical methodology}

We propose an empirical methodology in 3 steps. The first step consists to examine the stationarity properties of individual series in panel datasets using a battery of panel unit root tests. The second step develops the long-run relationship using appropriate panel long-run estimates (FMOLS and DOLS). Finally, the third step consists to estimate a panel VECM in order to study Granger causal relationships.

\subsection{Panel unit root tests analysis}

In this paper, three types of panel unit root test are computed in order to assess the stationary of the variables: Breitung (2001), Levin et al. (LLC, 2002) and Im et al. (IPS, 2003).

Breitung (2001) considered the following equation:

$$
W_{i t}=\alpha_{i t}+\sum_{j=1}^{k+1} \beta_{i j} \Delta X_{i, t-j}+\xi_{i t}
$$

In Eq. (8), the test statistic of Breitung (2001) assumes the following hypothesis: the null hypothesis is given by $H_{0}: \sum_{j=1}^{k+1} \beta_{i j}-1=0$, whereas the alternative hypothesis is given by $H_{1}: \sum_{j=1}^{k+1} \beta_{i j}-1<0$ and assumes that $W_{i t}$ is stationary. More precisely, Breitung (2001) uses the transformed vectors $w_{i}^{*}=A W_{i}=\left[W_{i 1}^{*}, W_{i 2}^{*}, \ldots, W_{i T}^{*}\right]^{\prime}$ and $x_{i}^{*}=A X_{i}=\left[X_{i 1}^{*}, X_{i 2}^{*}, \ldots, X_{i T}^{*}\right]^{\prime}$ in order to construct the following test statistic: 


$$
\lambda=\frac{\frac{1}{\sigma_{i}^{2}} \sum_{i=1}^{N} w_{i}^{* \prime} x_{i}^{* \prime}}{\sqrt{\frac{1}{\sigma_{i}^{2}} \sum_{i=1}^{N} x_{i}^{* \prime} A^{\prime} A x_{i}^{*}}}
$$

Levin et al. (LLC, 2002) proposed a panel unit root test based on ADF test and assumed the homogeneity in the dynamics of the autoregressive coefficients for all panel units with cross-sectional independence. They considered the following equation:

$$
\Delta X_{i t}=\alpha_{i}+\beta_{i} X_{i, t-1}+\delta_{i} t+\sum_{j=1}^{k} \gamma_{i j} \Delta X_{i, t-j}+v_{i t}
$$

where $\Delta$ is the first difference operator, $X_{i t}$ is the dependent variable, $\varepsilon_{i t}$ is a white-noise disturbance with a variance of $\sigma^{2}, i=1,2, \ldots, \mathrm{N}$ indexes country and $t=1,2, \ldots, \mathrm{T}$ indexes time.

Levin et al. (LLC, 2002) assumed:

$\left\{\begin{array}{l}H_{0}: \beta_{i}=0 \\ H_{1}: \beta_{i} \prec 0\end{array} ;\right.$

where alternative hypothesis corresponds to $Y_{i t}$ being stationary.

The test is based on the statistic $t_{\beta_{i}}=\hat{\beta}_{i} / \sigma\left(\hat{\beta}_{i}\right)$ (where $\hat{\beta}_{i}$ is the OLS estimate of $\beta_{i}$ in Eq. (10) and $\sigma\left(\hat{\beta}_{i}\right)$ is its standard error). Levin et al. (LLC, 2002) found that the panel approach substantially increases power in finite samples when compared with the singleequation ADF test. They also proposed a panel-based version of Eq. (11) that restricts $\hat{\beta}_{i}$ by keeping it identical across cross-countries as follows:

$$
\Delta X_{i t}=\alpha_{i}+\beta X_{i, t-1}+\delta_{i} t+\sum_{j=1}^{k} \gamma_{i j} \Delta X_{i, t-j}+v_{i t}
$$

At this level, Levin et al. (LLC, 2002) also assumed:

$\left\{\begin{array}{l}H_{0}: \beta_{1}=\beta_{2}=\ldots=\beta=0 \\ H_{1}: \beta_{1}=\beta_{2}=\ldots=\beta<0\end{array} ;\right.$

where the statistic of test is $t_{\beta}=\hat{\beta} / \sigma(\hat{\beta}), \hat{\beta}$ is the OLS estimate of $\beta$ in Eq. (11) and $\sigma(\hat{\beta})$ is its standard error.

Finall, the test of Im et al. (IPS, 2003) is based on the mean group approach. These authors used the average of the $t_{\beta_{i}}$ statistics from Eq. (10) in order to perform the following $\bar{Z}$ statistic: 


$$
\bar{Z}=\sqrt{N}[\bar{t}-E(\bar{t})] / \sqrt{V(\bar{t})}
$$

where $\bar{t}=\frac{1}{N} \sum_{i=1}^{N} t_{\beta_{i}}, E(\bar{t})$ and $V(\bar{t})$ are respectively the mean and variance of each $t_{\beta_{i}}$ statistic, and they are generated by simulations. $\bar{Z}$ converges to a standard normal distribution. This test is also based on the averaging individual unit root test, denoted by $\bar{t}=\frac{1}{N} \sum_{i=1}^{N} t_{\beta_{i}}$.

\subsection{Panel cointegration tests analysis}

Given that each of the variables contains a panel unit root, we proceed to examine whether there is a long-run relationship between the variables using Pedroni (1999, 2004) panel cointegration test.

Pedroni $(1999,2004)$ developed a number of statistics based on the residuals of the Engle and Granger (1987) cointegration regression. Assuming a panel of $\mathrm{N}$ countries, $\mathrm{T}$ observations and $\mathrm{m}$ regressors $\left(X_{m}\right)$, Pedroni $(1999,2004)$ considered the following equation:

$$
W_{i t}=\alpha_{i}+\lambda_{i} t+\sum_{j=1}^{m} \beta_{j, i} X_{j, i t}+\zeta_{i t}
$$

where $W_{i, t}$ and $X_{j, i, t}$ are integrated of order one in levels, i.e. I(1).

Pedroni $(1999,2004)$ proposed two sets of panel cointegration tests (see part I in Table 2). The first set, called panel cointegration tests, is based on the within dimension approach and includes four statistics: panel $v$ - statistic $\left(Z_{v}\right)$, panel rho-statistic $\left(Z_{\rho}\right)$, panel $P P$-statistic $\left(Z_{p p}\right.$ ), and panel $A D F$ - statistic $\left(Z_{A D F}\right)$. These statistics pool the autoregressive coefficients across different countries for the unit root tests on the estimated residuals taking into account common time factors and heterogeneity across countries. The second set, called group mean panel cointegration tests, is based on the between dimension approach and includes three statistics: group rho-statistic $\left(\tilde{Z}_{\rho}\right)$, group $P P$-statistic $\left(\tilde{Z}_{p p}\right)$, and group $A D F$-statistic $\left(\tilde{Z}_{A D F}\right)$. In general, these statistics are based on averages of the individual autoregressive coefficients associated with the unit root tests of the residuals for each country (for more details, see Farhani and Ben Rejeb, 2012).

Under null hypothesis, all seven tests indicate the absence of cointegration $H_{0}: \rho_{i}=0 ; \forall i$ , whereas the alternative hypothesis is given by $H_{1}: \rho_{i}=\rho \prec 1 ; \forall i$ where $\rho_{i}$ is the autoregressive term of the estimated residuals under the alternative hypothesis and it is given by in the following equation:

$$
\hat{\zeta}_{i, t}=\rho_{i} \cdot \hat{\zeta}_{i, t-1}+u_{i, t}
$$

Pedroni (1999) privileges that all seven statistics have a standard asymptotic distribution which is based on the independent movements in Brownian motions when $\mathrm{T}$ and $\mathrm{N} \rightarrow \infty$ : 


$$
\frac{Z-\mu \sqrt{N}}{\sqrt{v}} \underset{N, T \rightarrow \infty}{\longrightarrow} N(0,1)
$$

where $\mathrm{Z}$ is one of the seven normalized statistics, and $\mu$ and $v$ are tabulated in Pedroni (1999, Table 2).

\subsection{Panel FMOLS and DOLS estimates}

Although OLS estimators of the cointegrated vectors are superconvergent, their distribution is asymptotically biased and depends on nuisance parameters associated with the presence of serial correlation in the data (Kao and Chiang, 2001; Pedroni, 2001a, b). Many types of problems existed in the time series analysis may also arise for the panel data analysis and tend to be more marked even in the presence of heterogeneity (Kao and Chiang, 2001).

To carry out tests on the cointegrated vectors, it is consequently necessary to use methods of effective estimation. Various techniques exist, such as FMOLS estimator initially suggested by Phillips and Hansen (1990) and DOLS estimator of Saikkonen (1991) and Stock and Watson (1993). In the case of panel data, Kao and Chiang (2001) proved that these two techniques led to normally distributed estimators. They also proved that both OLS and FMOLS exhibit small sample bias and that DOLS estimator appears to outperform both estimators. Similar results are got by Phillips and Moon (1999) and Pedroni (2001a) for FMOLS estimator.

Returning to the FMOLS approach, the concerning estimator is used by Pedroni (2001a, b) to solve the problem of endogeneity between regressors. Thus, he considered the following equation:

$$
W_{i, t}=\alpha_{i}+\beta_{i} X_{i, t}+\tau_{i, t}
$$

where $W_{i t}$ and $X_{i, t}$ are cointegrated with slopes $\beta_{i}$, which may or may not be homogeneous across $i$. In similar spirit, Pedroni (2001a, b) proposed another equation by augmenting the cointegrating regression with lead and lagged differences of the regressor to control for the endogenous feedback effect. Consequently, Eq. (16) becomes:

$$
W_{i, t}=\alpha_{i}+\beta_{i} X_{i, t}+\sum_{k=-K_{i}}^{K_{i}} \gamma_{i, k} \Delta X_{i, t-k}+\tau_{i, t}
$$

They have also used to define $\omega_{i, t}=\left(\hat{\tau}_{i, t}, \Delta X_{i, t}\right)$; and let $\Omega_{i, t}=\lim _{T \rightarrow \infty} E\left[\frac{1}{T}\left(\sum_{t=1}^{T} \omega_{i, t}\right)\left(\sum_{t=1}^{T} \omega_{i, t}\right)^{\prime}\right]$ be the long-run covariance for this vector process. This long-run covariance matrix can be decomposed as $\Omega_{i}=\Omega_{i}^{0}+\Gamma_{i}+\Gamma_{i}^{\prime}$, where $\Omega_{i}^{0}$ is the contemporaneous covariance and $\Gamma_{i}$ is a weighted sum of autocovariances.

Thus, the panel FMOLS estimator will be given by: 


$$
\hat{\beta}_{F M O L S}^{*}=\frac{1}{N} \sum_{i=1}^{N}\left[\left(\sum_{t=1}^{T}\left(X_{i, t}-\bar{X}_{i}\right)^{2}\right)^{-1}\left(\sum_{t=1}^{T}\left(X_{i, t}-\bar{X}_{i}\right) W_{i, t}^{*}-T \hat{\gamma}_{i}\right)\right]
$$

where $W_{i, t}^{*}=W_{i, t}-\bar{W}_{i}-\frac{\hat{\Omega}_{2,1, i}}{\hat{\Omega}_{2,2, i}} \Delta X_{i, t}$ and $\hat{\gamma}_{i}=\hat{\Gamma}_{2,1, i}+\hat{\Omega}_{2,1, i}^{0}-\frac{\hat{\Omega}_{2,1, i}}{\hat{\Omega}_{2,2, i}}\left(\hat{\Gamma}_{2,2, i}+\hat{\Omega}_{2,2, i}^{0}\right)$.

According to the DOLS approach, that initially suggested by Saikkonen (1991) for the case of time series analysis and then adapted by Kao and Chiang (2001) and Mark and Sul (2003) for the case of panel data analysis, the concerning estimator is coming from Eq. 17 which includes advanced and delayed values $\left(\Delta \mathrm{X}_{\mathrm{i}, \mathrm{T}}\right)$ in the cointegrated relationship, in order to eliminate the correlation between regressors and error terms. Thus, the panel DOLS estimator can be defined as:

$$
\hat{\beta}_{D O L S}^{*}=\frac{1}{N} \sum_{i=1}^{N}\left[\left(\sum_{t=1}^{T} Z_{i, t} Z_{i, t}^{\prime}\right)^{-1}\left(\sum_{t=1}^{T} Z_{i, t} \tilde{W}_{i, t}\right)\right]
$$

where $Z_{i, t}=\left[X_{i, t}-\bar{X}_{i}, \Delta X_{i, t-K_{i}}, \ldots, \Delta X_{i, t+K_{i}}\right]$ is vector of regressors, and $\tilde{W}_{i, t}=W_{i, t}-\bar{W}_{i}$.

\subsection{Panel Granger causality test}

A panel VECM is estimated to perform Granger-causality tests (Pesaran et al., 1999). This panel followed by the two steps of Engle and Granger (1987) is employed to investigate the short- and long-run dynamic linkages. The first step consists to estimate the long-run parameters presented in Eqs. (6-7) in order to obtain the residuals corresponding to the deviation from equilibrium, while the second step consists to estimate the parameters related to the short-run adjustment.

The resulting equations are used in conjunction with panel Granger causality testing:

\section{Panel A.}




$$
\begin{aligned}
\left(\begin{array}{c}
\Delta C_{i, t} \\
\Delta Y_{i, t} \\
\Delta Y_{i, t}^{2} \\
\Delta E_{i, t} \\
\Delta T_{i, t} \\
\Delta M A N_{i, t} \\
\Delta M H I_{i, t}
\end{array}\right)=\left(\begin{array}{l}
\phi_{i, 1} \\
\phi_{i, 2} \\
\phi_{i, 3} \\
\phi_{i, 4} \\
\phi_{i, 5} \\
\phi_{i, 6} \\
\phi_{i, 7}
\end{array}\right)+\sum_{l=1}^{m}\left(\begin{array}{lllllll}
\theta_{1,1, k} & \theta_{1,2, k} & \theta_{1,3, k} & \theta_{1,4, k} & \theta_{1,5, k} & \theta_{1,6, k} & \theta_{1,7, k} \\
\theta_{2,1, k} & \theta_{2,2, k} & \theta_{2,3, k} & \theta_{2,4, k} & \theta_{2,5, k} & \theta_{2,6, k} & \theta_{2,7, k} \\
\theta_{3,1, k} & \theta_{3,2, k} & \theta_{3,3, k} & \theta_{3,4, k} & \theta_{3,5, k} & \theta_{3,6, k} & \theta_{3,7, k} \\
\theta_{4,1, k} & \theta_{4,2, k} & \theta_{4,3, k} & \theta_{4,4, k} & \theta_{4,5, k} & \theta_{4,6, k} & \theta_{4,7, k} \\
\theta_{5,1, k} & \theta_{5,2, k} & \theta_{5,3, k} & \theta_{5,4, k} & \theta_{5,5, k} & \theta_{5,6, k} & \theta_{5,7, k} \\
\theta_{6,1, k} & \theta_{6,2, k} & \theta_{6,3, k} & \theta_{6,4, k} & \theta_{6,5, k} & \theta_{6,6, k} & \theta_{6,7, k} \\
\theta_{7,1, k} & \theta_{7,2, k} & \theta_{7,3, k} & \theta_{7,4, k} & \theta_{7,5, k} & \theta_{7,6, k} & \theta_{7,7, k}
\end{array}\right) \\
\left(\begin{array}{c}
\Delta C_{i, t} \\
\Delta Y_{i, t} \\
\Delta Y_{i, t}^{2} \\
\Delta E_{i, t} \\
\Delta T_{i, t} \\
\Delta M A N_{i, t} \\
\Delta M D I_{i, t}
\end{array}\right)+\left(\begin{array}{l}
\lambda_{1} \\
\lambda_{2} \\
\lambda_{3} \\
\lambda_{4} \\
\lambda_{5} \\
\lambda_{6} \\
\lambda_{7}
\end{array}\right) \\
E C T_{i, t-1}+\left(\begin{array}{l}
\psi_{1, i, t} \\
\psi_{2, i, t} \\
\psi_{3, i, t} \\
\psi_{4, i, t} \\
\psi_{5, i, t} \\
\psi_{6, i, t} \\
\psi_{7, i, t}
\end{array}\right)
\end{aligned}
$$

\section{Panel B.}

$$
\begin{aligned}
\left(\begin{array}{c}
\Delta G S_{i, t}^{-} \\
\Delta H D I_{i, t} \\
\Delta H D I_{i, t}^{2} \\
\Delta E_{i, t} \\
\Delta T_{i, t} \\
\Delta M A N_{i, t} \\
\Delta R L_{i, t}
\end{array}\right)=\left(\begin{array}{c}
\omega_{i, 1} \\
\omega_{i, 2} \\
\omega_{i, 3} \\
\omega_{i, 4} \\
\omega_{i, 5} \\
\omega_{i, 6} \\
\omega_{i, 7}
\end{array}\right)+\sum_{l=1}^{m}\left(\begin{array}{lllllll}
\varpi_{1,1, k} & \varpi_{1,2, k} & \varpi_{1,3, k} & \varpi_{1,4, k} & \varpi_{1,5, k} & \varpi_{1,6, k} & \varpi_{1,7, k} \\
\varpi_{2,1, k} & \varpi_{2,2, k} & \varpi_{2,3, k} & \varpi_{2,4, k} & \varpi_{2,5, k} & \varpi_{2,6, k} & \varpi_{2,7, k} \\
\varpi_{3,1, k} & \varpi_{3,2, k} & \varpi_{3,3, k} & \varpi_{3,4, k} & \varpi_{3,5, k} & \varpi_{3,6, k} & \varpi_{3,7, k} \\
\varpi_{4,1, k} & \varpi_{4,2, k} & \varpi_{4,3, k} & \varpi_{4,4, k} & \varpi_{4,5, k} & \varpi_{4,6, k} & \varpi_{4,7, k} \\
\varpi_{5,1, k} & \varpi_{5,2, k} & \varpi_{5,3, k} & \varpi_{5,4, k} & \varpi_{5,5, k} & \varpi_{5,6, k} & \varpi_{5,7, k} \\
\varpi_{6,1, k} & \varpi_{6,2, k} & \varpi_{6,3, k} & \varpi_{6,4, k} & \varpi_{6,5, k} & \varpi_{6,6, k} & \varpi_{6,7, k} \\
\varpi_{7,1, k} & \varpi_{7,2, k} & \varpi_{7,3, k} & \varpi_{7,4, k} & \varpi_{7,5, k} & \varpi_{7,6, k} & \varpi_{7,7, k}
\end{array}\right) \\
\left(\begin{array}{c}
\Delta G S_{i, t-k}^{-} \\
\Delta H D I_{i, t-k} \\
\Delta H D I_{i, t-k}^{2} \\
\Delta E_{i, t-k} \\
\Delta T_{i, t-k} \\
\Delta M A N_{i, t-k} \\
\Delta R L_{i, t-k}
\end{array}\right)+\left(\begin{array}{c}
\gamma_{1} \\
\gamma_{2} \\
\gamma_{3} \\
\gamma_{4} \\
\gamma_{5} \\
\gamma_{6} \\
\gamma_{7}
\end{array}\right) E C T_{i, t-1}+\left(\begin{array}{lll}
v_{1, i, t} \\
v_{2, i, t} \\
v_{3, i, t} \\
v_{4, i, t} \\
v_{5, i, t} \\
v_{6, i, t} \\
v_{7, i, t}
\end{array}\right)
\end{aligned}
$$

where the term $\Delta$ denotes first differences; $\phi_{i, j}$ and $\omega_{i, k}(j, k=1,2,3,4,5,6,7)$ present the fixed country effect; $l(l=1, \ldots, \mathrm{m})$ is the optimal lag length determined by the Schwarz Information Criterion (SIC), and $E C T_{i, t-1}$ is the estimated lagged error correction term (ECT) derived from the long-run cointegrating relationship. The terms $\lambda_{j}$ and $\gamma_{k}$ are the adjustment coefficient; and $\psi_{j, i, t}$ and $v_{k, i, t}$ are the disturbance term, which assumed to be uncorrelated with zero means. 
At this level, we define the definite lagged residuals estimated in Eqs. (6-7) as the ECT, and we then estimate the parameters related to the two short-run models as follows:

EKC. $\quad E C T_{i, t}=C_{i, t}-\hat{\alpha}_{1, i} Y_{i, t}-\hat{\alpha}_{2, i} Y_{i, t}^{2}-\hat{\alpha}_{3, i} E_{i, t}-\hat{\alpha}_{4, i} T_{i, t}-\hat{\alpha}_{5, i} M A N_{i, t}-\hat{\alpha}_{6, i} M H D I_{i, t}$

MEKC. $E C T_{i, t}=G S_{i, t}^{-}-\hat{\beta}_{1, i} H D I_{i, t}-\hat{\beta}_{2, i} H D I_{i, t}^{2}-\hat{\beta}_{3, i} E_{i, t}-\hat{\beta}_{4, i} T_{i, t}-\hat{\beta}_{5, i} M A N_{i, t}-\hat{\beta}_{5, i} R L_{i, t}$

\section{Empirical results}

Table 1 shows the results of Breitung (2001), Levin et al. (LLC, 2002) and Im et al. (IPS, 2003) unit root tests. At the $1 \%$ significance level, the three unit root tests consistently confirm that all variables for the case of 10 MENA countries are integrated of order one, i.e. $\mathrm{I}(1)$.

Table 1

Panel unit root tests results.

\begin{tabular}{|c|c|c|c|c|c|c|c|c|}
\hline \multirow{4}{*}{ Breitung } & & C & $\mathbf{Y}$ & $\mathbf{E}$ & $\mathbf{T}$ & CS & HDI & $\mathbf{R L}$ \\
\hline & Level & -0.66158 & 2.56790 & -0.38610 & -1.69298 & -2.36211 & -0.07831 & -1.40811 \\
\hline & & $(0.9925)$ & $(0.9900)$ & $(0.1387)$ & $(0.67424)$ & $(0.9412)$ & $(0.4416)$ & $(0.9236)$ \\
\hline & $\Delta$ & $\begin{array}{l}-8.44314 * \\
(0.0000)\end{array}$ & $\begin{array}{l}-7.32983^{*} \\
(0.0000)\end{array}$ & $\begin{array}{l}-6.54872 * \\
(0.0000)\end{array}$ & $\begin{array}{l}-7.74738 * \\
(0.0000)\end{array}$ & $\begin{array}{l}-4.18363 * \\
(0.0000)\end{array}$ & $\begin{array}{l}-6.17533 * \\
(0.0000)\end{array}$ & $\begin{array}{l}-8.13563^{*} \\
(0.0000)\end{array}$ \\
\hline \multirow[t]{2}{*}{ LLC } & Level & -0.21857 & 1.00359 & -0.41585 & 0.03740 & -2.09498 & $\begin{array}{l}-0.69498 \\
\end{array}$ & -1.59498 \\
\hline & $\Delta$ & $\begin{array}{l}(0.9315) \\
-12.4283^{*} \\
(0.0000)\end{array}$ & $\begin{array}{l}(0.9578) \\
-8.6439 * \\
(0.0000)\end{array}$ & $\begin{array}{l}(0.5784) \\
-6.2088^{*} \\
(0.0000)\end{array}$ & $\begin{array}{l}(0.9519) \\
-8.85087 * \\
(0.0000)\end{array}$ & $\begin{array}{l}(0.9900) \\
-12.6174 * \\
(0.0001)\end{array}$ & $\begin{array}{l}(0.9556) \\
-5.62744^{*} \\
(0.0001)\end{array}$ & $\begin{array}{l}(0.8446) \\
-6.61764 * \\
(0.0001)\end{array}$ \\
\hline \multirow[t]{2}{*}{ IPS } & Level & $\begin{array}{l}-0.68081 \\
(0.9629)\end{array}$ & $\begin{array}{l}-1.72949 \\
(0.9319) \\
\end{array}$ & $\begin{array}{l}-0.17184 \\
(0.9412)\end{array}$ & $\begin{array}{l}0.92801 \\
(0.5263)\end{array}$ & $\begin{array}{l}-1.65842 \\
(0.9914)\end{array}$ & $\begin{array}{l}-1.65842 \\
(0.9990)\end{array}$ & $\begin{array}{l}1.63241 \\
(0.9514)\end{array}$ \\
\hline & $\Delta$ & $\begin{array}{l}-17.1239^{*} \\
(0.0000)\end{array}$ & $\begin{array}{l}-12.0086^{*} \\
(0.0000)\end{array}$ & $\begin{array}{l}-8.4302^{*} \\
(0.0000)\end{array}$ & $\begin{array}{l}-15.5816^{*} \\
(0.0000)\end{array}$ & $\begin{array}{l}-6.6404 * \\
(0.0000)\end{array}$ & $\begin{array}{l}-8.6604 * \\
(0.0000)\end{array}$ & $\begin{array}{l}-6.6239^{*} \\
(0.0000)\end{array}$ \\
\hline
\end{tabular}

All variables are in natural logarithms. $\Delta$ is the first difference operator. The null hypothesis of Breitung, LLC and IPS tests examines non-stationary. Lag selection (Automatic) is based on Schwarz Information Criteria (SIC).

* denotes statistical significance at the $1 \%$ level (P-values are presented in parentheses).

Since the variables are stationary at the first difference for both panel EKC and panel MEKC, the Pedroni's $(1999,2004)$ cointegration test will be utilized. Part II of Table 2 reviews Pedroni cointegration test results. The results show that all statistics are significant; thus, the null hypothesis of no cointegration can be rejected indicating that the variables are cointegrated, and also indicating that there are two long-run equilibrium relationships between all variables in Eqs. (6-7).

\section{Table 2}

Pedroni $(1999,2004)$ panel cointegration statistics and results.

\section{I- Within-dimension (four statistics)}

\section{Panel $v$-Statistic}

$Z_{v}=\left(\sum_{i=1}^{N} \sum_{t=1}^{T} \hat{L}_{1,1 i}^{-2} \hat{\zeta}_{i, t-1}^{2}\right)^{-1}$

2. Panel $\rho$-Statistic

$Z_{\rho}=\left(\sum_{i=1}^{N} \sum_{t=1}^{T} \hat{L}_{1,1 i}^{-2} \hat{\zeta}_{i, t-1}^{2}\right)^{-1} \sum_{i=1}^{N} \sum_{t=1}^{T} \hat{L}_{1,1 i}\left(\hat{\zeta}_{i, t-1} \Delta \hat{\zeta}_{i, t}-\hat{\lambda}_{i}\right)$

3. Panel non-parametric (PP) $t$-Statistic

1. Group $\rho$-Statistic

\section{Between-dimension (three statistics)}

$$
\tilde{Z}_{\rho}=\sum_{i=1}^{N}\left(\sum_{t=1}^{T} \hat{\zeta}_{i, t-1}^{2}\right)^{-1} \sum_{t=1}^{T}\left(\hat{\zeta}_{i, t-1} \Delta \hat{\zeta}_{i, t}-\hat{\lambda}_{i}\right)
$$

2. Group non-parametric (PP) $t$-Statistic 


$$
Z_{p p}=\left(\tilde{\sigma}^{2} \sum_{i=1}^{N} \sum_{t=1}^{T} \hat{L}_{1,1}^{-2} \hat{\zeta}_{i, t-1}^{2}\right)^{-1 / 2} \sum_{i=1}^{N} \sum_{t=1}^{T} \hat{L}_{1, i}^{-2}\left(\hat{\zeta}_{i, t-1} \Delta \hat{\zeta}_{i, t}-\hat{\lambda}_{i}\right) \quad \tilde{Z}_{p p}=\sum_{i=1}^{N}\left(\hat{\sigma}^{2} \sum_{t=1}^{T} \hat{\zeta}_{i, t-1}^{2}\right)^{-1 / 2} \sum_{t=1}^{T}\left(\hat{\zeta}_{i, t-1} \Delta \hat{\zeta}_{i, t}-\hat{\lambda}_{i}\right)
$$

4. Panel parametric (ADF) $t$-Statistic

$Z_{A D F}=\left(\hat{S}^{* 2} \sum_{i=1}^{N} \sum_{t=1}^{T} \hat{L}_{1,1 i}^{-2} \hat{\zeta}_{i, t-1}^{* 2}\right)^{-1 / 2} \sum_{i=1}^{N} \sum_{t=1}^{T} \hat{L}_{1,1 i}^{-2} \hat{\zeta}_{i, t-1}^{*} \Delta \hat{\zeta}_{i, t}^{*}$
3. Group parametric (ADF) $t$-Statistic

$\tilde{Z}_{A D F}=\sum_{i=1}^{N}\left(\sum_{t=1}^{T} \hat{S}_{i}^{-2} \hat{\zeta}_{i, t-1}^{* 2}\right)^{-1 / 2} \sum_{t=1}^{T} \hat{\zeta}_{i, t-1}^{*} \Delta \hat{\zeta}_{i, t}^{*}$

where;

i) $\hat{\lambda}_{i}=\frac{1}{T} \sum_{s=1}^{K}\left[1-\frac{s}{K_{i}+1}\right] \sum_{t=s+1}^{T} \hat{u}_{i, t} \hat{u}_{i, t-s}$ for $\hat{u}_{i, t}=\hat{\zeta}_{i, t}-\hat{\rho}_{i} \hat{\zeta}_{i, t-1}$;

ii) $\hat{L}_{1,1, i}^{-2}=\frac{1}{T} \sum_{t=1}^{K} \hat{\eta}_{i, t}^{2}+\frac{2}{T} \sum_{s=1}^{K}\left[1-\frac{s}{K_{i}+1}\right] \sum_{t=s+1}^{T} \hat{\eta}_{i, t} \hat{\eta}_{i, t-s}$ for $\hat{\eta}_{i, t}=\Delta Y_{i t}-\sum_{m=1}^{M} \hat{b}_{m, i} \Delta X_{m, i t}$;

iii) $\tilde{\sigma}^{2}=\frac{1}{N} \sum_{i=1}^{N} \hat{L}_{1,1 i}^{-2} \hat{\sigma}_{i}^{2}$ for $\hat{\sigma}_{i}^{2}=\hat{S}_{i}^{2}+2 \hat{\lambda}_{i} ;$ and

iv) $\hat{S}_{i}^{2}=\frac{1}{T} \sum_{t=1}^{T} \hat{u}_{i, t}^{2} ; \hat{S}_{i}^{* 2}=\frac{1}{T} \sum_{t=1}^{T} \hat{u}_{i, t}^{* 2}$ for $\hat{u}_{i, t}^{*}=\hat{\zeta}_{i, t}-\hat{\rho}_{i} \hat{\zeta}_{i, t-1}-\sum_{k=1}^{K_{i}} \hat{\rho}_{i, k} \Delta \hat{\zeta}_{i, t-k}$.

\begin{tabular}{|c|c|c|c|c|c|}
\hline \multirow{2}{*}{$\begin{array}{l}\text { II- } \\
\text { Within-dimension }\end{array}$} & \multicolumn{2}{|c|}{ Panel EKC } & \multirow[b]{2}{*}{ Within-dimension } & \multicolumn{2}{|c|}{ Panel MEKC } \\
\hline & Test statistic & Prob. & & Test statistic & Prob. \\
\hline Panel v-stat & $-4.295621 *$ & $(0.0005)$ & Panel v-stat & $-2.459921 *$ & $(0.0091)$ \\
\hline Panel r-stat & $-1.371653 * *$ & $(0.0299)$ & Panel r-stat & $-2.992586^{*}$ & $(0.0039)$ \\
\hline Panel PP-stat & $-4.246129 *$ & $(0.0000)$ & Panel PP-stat & $-3.669440 *$ & $(0.0005)$ \\
\hline PanelADF-stat & $-4.435313^{*}$ & $(0.0000)$ & PanelADF-stat & $-3.715221 *$ & $(0.0004)$ \\
\hline Between-dimension & & & Between-dimension & & \\
\hline Group r-stat & $-1.983122^{* *}$ & $(0.0242)$ & Group r-stat & $-2.350068 * *$ & $(0.0105)$ \\
\hline Group PP-stat & $-4.326689 *$ & $(0.0000)$ & Group PP-stat & $-4.285792 *$ & $(0.0000)$ \\
\hline GroupADF-stat & $-3.247851 *$ & $(0.0010)$ & GroupADF-stat & $-4.717762 *$ & $(0.0000)$ \\
\hline
\end{tabular}

The null hypothesis of Pedroni test examines the absence of cointegration. Lag selection (Automatic) is based on SIC with a max lag of 5 . $*$ and $* *$ denote statistical significance at the 1 and $5 \%$ levels, respectively.

Table 3 and Table 4 provide the results of panel FMOLS and DOLS estimates for EKC and MEKC, respectively. All variables are expressed in natural logarithms. The estimated coefficients from the long-run cointegration relationship can be interpreted as long-run elasticities. In all cases, the parameters are quite significant at the $1 \%$ level of significance. Concerning the verification of the standard EKC hypothesis, the results indicate that there are inverse U-shaped relationships between $\mathrm{CO}_{2}$ emissions per capita and per capita real GDP for EKC model (i.e. Eq. (6)) and between negative Genuine Saving per capita (GS ${ }^{-}$) and HDI for MEKC model (i.e. Eq. (7)). This means that the appropriate hypothesis is very well verified for both EKC and MEKC models.

With respect to panel EKC model presented Table 3, the coefficients from panel FMOLS estimation are 2.095, -0.101, 1.828, 0.216, 0.072 and 1.782 for $Y, Y^{2}, E, T, M A N$ and MHDI, respectively. This means that in the long-run the elasticity of $\mathrm{CO}_{2}$ emissions per capita with respect to per capita real GDP is $2.095-0.202 . Y$; a $1 \%$ increase in energy consumption per capita increases $\mathrm{CO}_{2}$ emissions per capita by $1.828 \%$; a $1 \%$ increase in trade openness increases $\mathrm{CO}_{2}$ emissions per capita by $0.216 \%$; a $1 \%$ increase in manufacture value added increases $\mathrm{CO}_{2}$ emissions per capita by $0.072 \%$; and a $1 \%$ increase in MHDI increases $\mathrm{CO}_{2}$ emissions per capita by $1.782 \%$. However, the coefficients from panel DOLS estimation are 2.081, $-0.100,1.812,0.212,0.069$ and 2.216 for $Y, Y^{2}, E, T, M A N$ and MHDI, respectively. This means that in the long-run the elasticity of $\mathrm{CO}_{2}$ emissions per capita with respect to per 
capita real GDP is $2.081-0.200 . Y$; a $1 \%$ increase in energy consumption per capita increases $\mathrm{CO}_{2}$ emissions per capita by approximately $1.812 \%$; a $1 \%$ increase in trade openness increases $\mathrm{CO}_{2}$ emissions per capita by $0.212 \%$; a $1 \%$ increase in manufacture value added increases $\mathrm{CO}_{2}$ emissions per capita by $0.069 \%$; and a $1 \%$ increase in MHDI increases $\mathrm{CO}_{2}$ emissions per capita by $2.216 \%$.

Table 3

Panel FMOLS and DOLS results for EKC (C as dependent variable).

\begin{tabular}{cccccccc}
\hline Panel & $\mathbf{Y}$ & $\mathbf{Y}^{2}$ & $\mathbf{E}$ & $\mathbf{T}$ & MAN & MHDI & Constant \\
\hline FMOLS & $2.095^{*}$ & $-0.101^{*}$ & $1.828^{*}$ & $0.216^{*}$ & $0.072^{*}$ & $1.782^{*}$ & $-6.216^{*}$ \\
& $(0.0000)$ & $(0.0000)$ & $(0.0000)$ & $(0.0000)$ & $(0.0000)$ & $(0.0000)$ & $(0.0000)$ \\
\multirow{2}{*}{ DOLS } & & & & & & & \\
& $2.081^{*}$ & $-0.100^{*}$ & $1.812^{*}$ & $0.212^{*}$ & $0.069^{*}$ & $2.216^{*}$ & $-8.478^{*}$ \\
& $(0.0000)$ & $(0.0000)$ & $(0.0005)$ & $(0.0001)$ & $(0.0000)$ & $(0.0000)$ & $(0.0000)$ \\
\hline
\end{tabular}

$*$ denotes statistical significance at the $1 \%$ level. P-values are reported in parentheses.

With respect to panel MEKC model presented in Table 4, the coefficients from panel FMOLS estimation are 1.895, -1.024, 1.178, 0.225, 0.065 and -0.016 for $H D I, H D I^{2}, E, T$, $M A N$ and $R L$, respectively. This means that in the long-run the elasticity of $\mathrm{GS}^{-}$per capita with respect to the HDI is $1.895-2.048 . \mathrm{HDI}$; a $1 \%$ increase in energy consumption per capita increases $\mathrm{GS}^{-}$per capita by $1.178 \%$; a $1 \%$ increase in trade openness increases $\mathrm{GS}^{-}$per capita by $0.225 \%$; a $1 \%$ increase in manufacture value added increases $\mathrm{GS}^{-}$per capita by $0.065 \%$; and a $1 \%$ increase in RL related to the control of corruption decreases $\mathrm{GS}^{-}$per capita by $0.016 \%$. However, the coefficients from panel DOLS estimation are 2.094, -1.001, 1.128, $0.279,0.067$ and -0.021 for $H D I, H D I^{2}, E, T, M A N$ and $R L$, respectively. This means that in the long-run the elasticity of $\mathrm{GS}^{-}$per capita with respect to HDI is $2.094-2.002 . \mathrm{HDI}$; a $1 \%$ increase in energy consumption per capita increases GS ${ }^{-}$per capita by $1.128 \%$; a $1 \%$ increase in trade openness increases $\mathrm{GS}^{-}$per capita by $0.279 \%$; a $1 \%$ increase in manufacture value added increases $\mathrm{GS}^{-}$per capita by $0.067 \%$; and a $1 \%$ increase in RL related to the control of corruption decreases $\mathrm{GS}^{-}$per capita by $0.021 \%$.

Table 4

FMOLS and DOLS results for MEKC ( $\mathrm{GS}^{-}$as dependent variable).

\begin{tabular}{cccccccc}
\hline Panel & HDI & HDI $^{2}$ & E & T & MAN & RL & Constant \\
\hline FMOLS & $1.895^{*}$ & $-1.024^{*}$ & $1.178^{*}$ & $0.225^{*}$ & $0.065^{*}$ & $-0.016^{*}$ & $-6.478^{*}$ \\
& $(0.0020)$ & $(0.0075)$ & $(0.0000)$ & $(0.0001)$ & $(0.0000)$ & $(0.0045)$ & $(0.0000)$ \\
\multirow{2}{*}{ DOLS } & & & & & & & \\
& $2.094^{*}$ & $-1.001^{*}$ & $1.128^{*}$ & $0.279^{*}$ & $0.067^{*}$ & $-0.021^{*}$ & $-5.982^{*}$ \\
& $(0.0004)$ & $(0.0050)$ & $(0.0000)$ & $(0.0000)$ & $(0.0000)$ & $(0.0040)$ & $(0.0000)$ \\
\hline
\end{tabular}

$*$ denotes statistical significance at the $1 \%$ level. P-values are reported in parentheses.

The panel short- and long-run Granger causality results conducted to Eq. (20) for EKC model and Eq. (21) for MEKC model are reported in Table 5. The statistical significance of the coefficients associated with the ECT provides evidence of an error correction mechanism that drives the variables back to their long-run relationship. According to the coefficient on the lagged ECT, there exists a long-run relationship among the variables in the form of Eq. (6) for EKC and Eq. (7) for MEKC, where all coefficients are statistically significant. The findings also indicate that there exists bi-directional Granger causality between all variables.

With respect to Eq. (6), Eq. (20) and Eq. (22), the results from EKC model estimation indicate that real GDP per capita, energy consumption per capita, trade openness, manufacture value added, and MHDI exert a causal significant effect on $\mathrm{CO}_{2}$ emissions per capita. 
Moreover, the ECT is statistically significant at the $1 \%$ level which suggests that all variables present a relative slow speed of adjustment to long-run equilibrium.

With respect to Eq. (7), Eq. (21) and Eq. (23), the results from MEKC model estimation indicate that HDI, energy consumption, trade openness, manufacture value added, and RL exert a causal significant effect on the $\mathrm{GS}^{-}$per capita. Moreover, the ECT is statistically significant at the $10 \%$ level which suggests that all variables present a relative slow speed of adjustment to long-run equilibrium.

In addition, it is important to note that there are bidirectional causality relationships between all variables for both EKC and MEKC; and that the ECT is statistically significant for other variables.

Table 5

Panel causality test results.

\begin{tabular}{|c|c|c|c|c|c|c|c|}
\hline \multirow{2}{*}{$\begin{array}{c}\begin{array}{c}\text { Dependent } \\
\text { Variable }\end{array} \\
\text { EKC }\end{array}$} & \multicolumn{6}{|c|}{$\begin{array}{c}\text { Short run } \\
\text { Sources of causation (Independent variable) }\end{array}$} & \multirow{2}{*}{$\begin{array}{c}\text { Long run } \\
\text { ECT }\end{array}$} \\
\hline & $\Delta \mathrm{C}$ & $\Delta \mathbf{Y}\left(\Delta \mathbf{Y}^{2}\right)$ & $\Delta \mathbf{E}$ & $\Delta T$ & AMAN & AMHDI & \\
\hline$\Delta \mathrm{C}$ & $\#$ & $\begin{array}{c}6.249^{*} \\
(0.0005)\end{array}$ & $\begin{array}{l}5.556^{* *} \\
(0.0124)\end{array}$ & $\begin{array}{c}0.895^{*} \\
(0.0029)\end{array}$ & $\begin{array}{c}0.108^{*} \\
(0.0044)\end{array}$ & $\begin{array}{c}0.008^{*} \\
(0.0000)\end{array}$ & $\begin{array}{c}-0.522 * \\
{[-4.59297]}\end{array}$ \\
\hline$\Delta \mathbf{Y}\left(\Delta \mathbf{Y}^{2}\right)$ & $\begin{array}{r}0.116 * * * \\
(0.0939)\end{array}$ & $\#$ & $\begin{array}{c}0.138^{*} \\
(0.0068)\end{array}$ & $\begin{array}{l}0.654 * * \\
(0.0405)\end{array}$ & $\begin{array}{c}1.652^{*} \\
(0.0055)\end{array}$ & $\begin{array}{l}1.069^{*} \\
(0.0004)\end{array}$ & $\begin{array}{l}-0.018 * * \\
{[-2.44805]}\end{array}$ \\
\hline$\Delta \mathbf{E}$ & $\begin{array}{l}1.090^{*} \\
(0.0036)\end{array}$ & $\begin{array}{l}0.079 * * \\
(0.0240)\end{array}$ & $\#$ & $\begin{array}{l}1.050^{* *} \\
(0.0310)\end{array}$ & $\begin{array}{l}2.047 * \\
(0.0010)\end{array}$ & $\begin{array}{l}0.050^{*} \\
(0.0000)\end{array}$ & $\begin{array}{c}-0.215^{*} \\
{[-2.93596]}\end{array}$ \\
\hline$\Delta \mathrm{T}$ & $\begin{array}{l}2.437 * \\
(0.0055)\end{array}$ & $\begin{array}{c}0.911 * \\
(0.0000)\end{array}$ & $\begin{array}{l}1.058 * * * \\
(0.0710)\end{array}$ & $\#$ & $\begin{array}{c}0.199 * \\
(0.0035)\end{array}$ & $\begin{array}{c}0.122 * \\
(0.0010)\end{array}$ & $\begin{array}{c}-0.665^{*} \\
{[-6.33271]}\end{array}$ \\
\hline$\triangle M A N$ & $\begin{array}{l}1.772 * * \\
(0.0136)\end{array}$ & $\begin{array}{r}0.309 * * * \\
(0.0910)\end{array}$ & $\begin{array}{l}6.150^{*} \\
(0.0010)\end{array}$ & $\begin{array}{r}2.004 * * * \\
(0.0787)\end{array}$ & $\#$ & $\begin{array}{l}1.001 * \\
(0.0000)\end{array}$ & $\begin{array}{c}-0.105 * * \\
{[-2.07346]}\end{array}$ \\
\hline$\Delta$ MHDI & $\begin{array}{l}0.965^{* *} \\
(0.0419) \\
\end{array}$ & $\begin{array}{l}1.305 * * * \\
(0.0575) \\
\end{array}$ & $\begin{array}{l}1.660 * * * \\
(0.0916) \\
\end{array}$ & $\begin{array}{c}0.864 * \\
(0.0000) \\
\end{array}$ & $\begin{array}{c}3.050^{*} \\
(0.0000) \\
\end{array}$ & $\#$ & $\begin{array}{c}-0.870^{*} \\
{[-5.74562]} \\
\end{array}$ \\
\hline MEKC & $\Delta \mathbf{G S}^{-}$ & $\Delta \mathrm{HDI}\left(\Delta \mathrm{HDI}^{2}\right)$ & $\Delta \mathbf{E}$ & $\Delta T$ & $\triangle M A N$ & $\Delta \mathbf{R L}$ & ECT \\
\hline$\Delta \mathbf{G S}^{-}$ & $\#$ & $\begin{array}{c}1.925^{*} \\
(0.0025)\end{array}$ & $\begin{array}{l}2.237 * \\
(0.0020)\end{array}$ & $\begin{array}{l}0.752^{* * * *} \\
(0.0900)\end{array}$ & $\begin{array}{c}1.019^{*} \\
(0.0000)\end{array}$ & $\begin{array}{c}6.524 * \\
(0.0000)\end{array}$ & $\begin{array}{c}-2.321 * \\
{[-5.36147]}\end{array}$ \\
\hline$\Delta \mathrm{HDI}\left(\Delta \mathrm{HDI}^{2}\right)$ & $\begin{array}{l}1.274 * \\
(0.0024)\end{array}$ & $\#$ & $\begin{array}{l}2.122 * \\
(0.0000)\end{array}$ & $\begin{array}{l}0.997 * * \\
(0.0780)\end{array}$ & $\begin{array}{l}2.138^{*} \\
(0.0002)\end{array}$ & $\begin{array}{c}1.002 * \\
(0.0001)\end{array}$ & $\begin{array}{c}-5.412 * \\
{[-4.12651]}\end{array}$ \\
\hline$\Delta \mathbf{E}$ & $\begin{array}{l}7.008^{*} \\
(0.0000)\end{array}$ & $\begin{array}{l}1.412 * \\
(0.0050)\end{array}$ & $\#$ & $\begin{array}{l}3.055^{*} \\
(0.0010)\end{array}$ & $\begin{array}{c}1.071^{*} \\
(0.0055)\end{array}$ & $\begin{array}{l}2.778 * * \\
(0.0445)\end{array}$ & $\begin{array}{c}-1.395^{*} \\
{[-2.77536]}\end{array}$ \\
\hline$\Delta \mathrm{T}$ & $\begin{array}{l}0.090^{* *} \\
(0.0136)\end{array}$ & $\begin{array}{l}1.122 * \\
(0.0040)\end{array}$ & $\begin{array}{l}3.913 * \\
(0.0004)\end{array}$ & $\#$ & $\begin{array}{l}1.648^{*} \\
(0.0000)\end{array}$ & $\begin{array}{l}3.297 * * * \\
(0.0657)\end{array}$ & $\begin{array}{c}-2.665^{*} \\
{[-4.28279]}\end{array}$ \\
\hline$\triangle M A N$ & $\begin{array}{l}1.474^{*} \\
(0.0050)\end{array}$ & $\begin{array}{c}3.378^{*} \\
(0.0040)\end{array}$ & $\begin{array}{l}1.909^{* *} \\
(0.0505)\end{array}$ & $\begin{array}{r}0.227 * * * \\
(0.0971)\end{array}$ & $\#$ & $\begin{array}{l}2.122 * \\
(0.0000)\end{array}$ & $\begin{array}{c}-1.802 * \\
{[-2.97296]}\end{array}$ \\
\hline$\Delta \mathbf{R L}$ & $\begin{array}{c}1.899^{*} \\
(0.0001)\end{array}$ & $\begin{array}{c}0.471^{*} \\
(0.0085)\end{array}$ & $\begin{array}{c}0.096^{*} \\
(0.0000)\end{array}$ & $\begin{array}{l}1.334 * * \\
(0.0445)\end{array}$ & $\begin{array}{l}0.398 * * \\
(0.0304)\end{array}$ & $\#$ & $\begin{array}{c}-2.226 * * \\
{[-2.13282]}\end{array}$ \\
\hline
\end{tabular}

Short-run causality is determined by the statistical significance of the partial F-statistics associated with the right hand side variables. Long-run causality is revealed by the statistical significance of the respective error correction terms using a t-test. P-values are listed in parentheses and t-statistics are presented in brackets.

$*, * *$ and $* * *$ denote statistical significance at the 1,5 and $10 \%$ levels, respectively. 


\section{Conclusion and policy implications}

There is an extensive literature looking at the traditional EKC literature, but without developing factors related to sustainable development path. The lack of studies that explored this point motivates us to parallelly examine two models. The first one is based on the traditional EKC literature, which included $\mathrm{CO}_{2}$ emissions per capita, per capita real GDP, energy consumption per capita, trade openness, manufacture value added and modified HDI that does not include GDP; while for the second model, a new concept of modified EKC literature has been shown in order to relate negative GS per capita, HDI, energy consumption per capita, trade openness, manufacture value added and the rule of law as one important dimension of governance in the control of corruption.

To achieve the main goal of this study, our panel models were likewise established using 10 Middle East and North African (MENA) countries over the period 1990-2010. Three different panel unit root tests, Breitung (2001), Levin et al. (LLC, 2002) and Im et al. (IPS, 2003), are applied to support that all the panel variables are integrated of order one, i.e. I(1). The Pedroni $(1999,2004)$ panel cointegration test results was also applied to support that all the panel variables are cointegrated.

With respect to EKC, the "means" of FMOLS and DOLS coefficients are 2.088, -0.100, $1.820,0.214,0.070$ and 2 for $Y, Y^{2}, E, T, M A N$ and $M H D I$, respectively. This means that in the long-run the elasticity of $\mathrm{CO}_{2}$ emissions per capita with respect per capita real GDP is 2.088 $0.200 . Y$; a $1 \%$ increase in energy consumption per capita increases $\mathrm{CO}_{2}$ emissions per capita by approximately $1.820 \%$; a $1 \%$ increase in trade openness increases $\mathrm{CO}_{2}$ emissions per capita by approximately $0.214 \%$; a $1 \%$ increase in manufacture value added increases $\mathrm{CO}_{2}$ emissions per capita by approximately $0.070 \%$; and a $1 \%$ increase in MHDI increases $\mathrm{CO}_{2}$ emissions per capita by approximately $2 \%$.

With respect to MEKC, the "means" of FMOLS and DOLS coefficients are 1.995, -1.012, $1.153,0.2252,0.066$ and -0.019 for $H D I, H D I^{2}, E, T, M A N$ and $R L$, respectively. This means that in the long-run the elasticity of negative GS per capita per capita with respect to the HDI is $1.995-2.024 . H D I$; a $1 \%$ increase in energy consumption per capita increases negative Genuine Saving per capita by approximately $1.153 \%$; a $1 \%$ increase in trade openness increases negative Genuine Saving per capita by approximately $0.252 \%$; a $1 \%$ increase in manufacture value added increases negative Genuine Saving per capita by approximately $0.066 \%$; and a $1 \%$ increase in the rule of law decreases negative Genuine Saving per capita by approximately $0.019 \%$.

Short- and long-run causality results have important implications for environmental policy as soon as the statistical significance of the coefficients associated with the ECT provides evidence of an error correction mechanism that drives the variables back to their long-run relationship. In addition, there exist long and short-run bidirectional relationships among the variables for EKC and MEKC as all coefficients are statistically significant.

The first implication is that, with respect to EKC, achieving an adequate sustainability level with a positive capital accumulation process is a very difficult task during the first stage of development. The satisfaction of basic HD needs is a necessary condition for such an objective and environmental protection is considered a secondary good. Nevertheless, applying an MEKC it seems that it is possible to reduce an unsustainable growth path at a medium level of development, while the reversing environmental degradation using EKC seems to occur in correspondence with high income levels (Costantini and Monni, 2008).

The second implication is that HD represents valuable means to reach and to maintain higher sustainability path in the future. The resource curse would not occur if appropriate investments in HD have been placed; thus, producing consistent positive effects in terms of the quality of the pollution and sustainability. Better institutions represent one of the most 
effective conditional variables for higher economic growth, together with private capital investments. This element is perfectly in line with conditional convergence of Barro and Salai-Martin (1995), where higher savings rates are one of the variables which increase the economic growth rate and the steady-state income level.

A third implication concerns the specific role of trade openness process. From our analysis there is no specific sign that the trade openness could bring positive effects to developing countries. On the same, according to Stiglitz (2000), trade openness and foreign direct investment (FDI) inflows positively affect the quality of institutions. At this level, the globalization ceteris paribus could be a source of governance improvements for the economies exposed to increasing trade and capital inflows. At the same time, countries need to know how to invest the advantages they derive from such a process for the improvement of $\mathrm{HD}$, without wasting available resources. A fourth implication states the analysis concerning corruption related with rule of law. In order to avoid a weak rule of law supported to a high level of corruption, the World Bank should consider rules that control corruption, because, as know, the countries with a high rule of law ensure that no one is above the law and thus the corruption may decrease (Kaufman et al., 2003; de Mendonça and da Fonseca, 2012).

\section{References}

Abou-Ali, H., Abdelfattah, Y.M., 2013. Integrated paradigm for sustainable development: A panel data study. Econ. Model. 30, 334-342.

Andreoni, J., Levinson, A., 2001. The simple analytics of the environmental Kuznets curve. J. Public Econ. 80, $269-286$.

Ang, J.B., 2007. $\mathrm{CO}_{2}$ emissions, energy consumption, and output in France. Energy Policy 35, 4772-4778.

Ang, J.B., 2009. $\mathrm{CO}_{2}$ emissions, research and technology transfer in China. Ecol. Econ. 68, 2658-2665.

Antweiler, W., Copeland, B.R., Taylor, M.S., 2001. Is free trade good for the environment? Am. Econ. Rev. 91, 877-908.

Apergis, N., Payne, J.E., 2009. $\mathrm{CO}_{2}$ emissions, energy usage, and output in Central America. Energy Policy 37 , 3282-3286.

Apergis, N., Payne, J.E., 2010. The emissions, energy consumption, and growth nexus: Evidence from the commonwealth of independent states. Energy Policy 38, 650-655.

Arouri, M.H., Ben Youssef, A., M'Henni, H., Rault, C., 2012. Energy consumption, economic growth and $\mathrm{CO}_{2}$ emissions in Middle East and North African countries. Energy Policy 45, 342-349.

Arouri M., Shahbaz M., Onchang R., Islam F., Teulon F., 2014. Environmental Kuznets Curve in Thailand: Cointegration and Causality Analysis, Ipag working paper, n²04.

Arrow, K., Bolin, B., Costanza, R., Dasgupta, P., Folke, C., Holling, C.S., Jansson, B.-O., Levin, S., Maler, K.G., Perrings, C., Pimentel, D., 1996. Economic growth, carrying capacity, and the environment. Ecol. Appl. 6, 13-15.

Babu, S.S., Datta, S.K., 2013. The relevance of environmental Kuznets curve (EKC) in a framework of broadbased environmental degradation and modified measure of growth - a pooled data analysis. Int. J. Sustain. Dev. World Ecol. 20, 309-316.

Baltagi, B.H., 2005. Econometric Analysis of Panel Data, third ed. John Wiley \& Sons, Chichester.

Barro, R.J., Sala-i-Martin, X., 1995. Economic Growth, first ed. McGraw-Hill, Boston, MA.

Breitung, J., 2001. The local power of some unit root tests for panel data, in: Baltagi B.H., Fomby, T.B., Hill, R.C. (Eds.), Nonstationary Panels, Panel Cointegration, and Dynamic Panels (Advances in Econometrics, Vol.15). Emerald Group Publishing Limited, United Kingdom, pp. 161-177.

Cole, M.A., 2004. Trade, the pollution haven hypothesis and the environmental Kuznets curve: examining the linkages. Ecol. Econ. 48, 71-81.

Cole, M.A., Elliott, R.J.R., 2003. Determining the trade-environment composition effect: the role of capital, labor and environmental regulations. J. Environ. Econ. Manag. 46, 363-383.

Costantini, V., Martini, C., 2010. A Modified Environmental Kuznets Curve for sustainable development assessment using panel data. Int. J. Glob. Environ. Issues 10, 84-122.

Costantini, V., Monni, S., 2008. Environment, human development and economic growth. Ecol. Econ. 64, 867880.

Dasgupta, S., Hamilton,K., Pandey, K.D., Wheeler, D., 2006. Environment During growth: Accounting for governance and vulnerability. World Dev. 34, 1597-1611. 
de Mendonça, H.F., da Fonseca, A.O., 2012. Corruption, income, and rule of law: empirical evidence from developing and developed economies. Braz. J. Polit. Econ. 32, 305-314.

Egli, H., 2002. Are cross-country studies of the environmental Kuznets curve misleading? New Evidence from time series aata for Germany. FEEM Work. Pap. No. 25.

Engle, R.F., Granger, C.W.J., 1987. Co-integration and error correction: Representation, estimation, and testing. Econom. 55, 251-276.

Farhani, S., Ben Rejeb, J., 2012. Link between economic growth and energy consumption in over 90 countries. Interdiscip. J. Contemp. Res. Bus. 3, 282-297.

Farhani, S., Chaibi, A., Rault, C., 2014a. $\mathrm{CO}_{2}$ emissions, output, energy consumption, and trade in Tunisia. Econ. Model. 38, 426-434.

Farhani, S., Shahbaz, M., Sbia, R., Chaibi, A., 2014b. What does MENA region initially need: Grow output or mitigate $\mathrm{CO}_{2}$ emissions? Econ. Model. 38, 270-281.

Farzin, Y.H., Bond, C., 2006. Democracy and environmental quality. J. Dev. Econ. 81, 213-235.

Gangadharan, L., Valenzuela, M.R., 2001. Interrelationships between income, health and the environment: extending the Environmental Kuznets Curve hypothesis. Ecol. Econ. 36, 513-531.

Grossman, G., Krueger, A., 1995. Economic growth and the environment. Q. J. Econ. 110, 353-377.

Halicioglu, F., 2009. An econometric study of $\mathrm{CO}_{2}$ emissions, energy consumption, income and foreign trade in Turkey. Energy Policy 37, 1156-1164.

Hamilton, K., 2000. Genuine Savings as a sustainability indicator. Environ. Econ. Ser. No.77.

Hartman, R., Kwon, O-S. 2005. Sustainable growth and the environmental Kuznets curve. J. Econ. Dyn. Control 29, 1701-1736.

Hettige, H., Mani, M., Wheeler, D., 2000. Industrial pollution in economic development, the environmental Kuznets curve revisited. J. Dev. Econ. 62, 445-476.

Hill, R.J., Magnani, E., 2002. An exploration of the conceptual and empirical basis of the environmental Kuznets curve. Aust. Econ. Pap. 41, 239-254.

Huntington, S.P., 1968. Political Order in Changing Societies. Yale University Press, New Haven.

Im, K.S., Pesaran, M.H., Shin, Y., 2003. Testing for unit roots in heterogeneous panels. J. Econom. 115, 53-74.

Jalil, A., Mahmud, S.F., 2009. Environment Kuznets curve for $\mathrm{CO}_{2}$ emissions: A cointegration analysis for China. Energy Policy 37, 5167-5172.

Jayanthakumaran, K., Verma, R., Liu, Y., 2012. $\mathrm{CO}_{2}$ emissions, energy consumption, trade and income: A comparative analysis of China and India. Energy Policy 42, 450-460.

Jha, R., Murthy, K.V.B., 2003. An inverse global environmental Kuznets curve. J. Comp. Econ. 31, 352-368.

Jun, Y., Zhong-kui, Y., Peng-fei, S., 2011. Income distribution, human capital and environmental quality: Empirical study in China. Energy Procedia 5, 1689-1696.

Kao. C., Chiang, M.H., 2001. On the estimation and inference of a cointegrated regression in panel data, in: Baltagi B.H., Fomby, T.B., Hill, R.C. (Eds.), Nonstationary Panels, Panel Cointegration, and Dynamic Panels (Advances in Econometrics, Vol.15). Emerald Group Publishing Limited, United Kingdom, pp. 179-222.

Kaufman, D., Kraay, A., Mastruzzi, M., 2003. Governance Matters III: Governance Indicators for 1996-2002. Policy Res. Work. Pap. No. 3106.

Kijima, M., Nishide, K., Ohyama, A., 2010. Economic models for the environmental Kuznets curve: A Survey. J. Econ. Dyn. Control 34, 1187-1201.

Lean, H.H., Smyth, R., 2010. $\mathrm{CO}_{2}$ emissions, electricity consumption and output in ASEAN. Appl. Energy 87, 1858-1864.

Leff, N.H., 1964. Economic development through bureaucratic corruption. Am. Behav. Sci. 8, 8-14.

Levin, A., Lin, C.F., Chu, C.S., 2002. Unit root tests in panel data: Asymptotic and finite-sample properties. J. Econom. 108, 1-24.

Liu, L., 2012. Environmental poverty, a decomposed environmental Kuznets curve, and alternatives: Sustainability lessons from China. Ecol. Econ. 73, 86-92.

Lopez, R., Mitra, S., 2000. Corruption, pollution, and the Kuznets environment curve. J. Environ. Econ. Manag. 40, 137-150.

Magnani, E., 2000. The Environmental Kuznets Curve, environmental protection policy and income distribution. Ecol. Econ. 32, 431-443.

Mark, N.C., Sul, D., 2003. Cointegration vector estimation by panel DOLS and long-run money demand. Oxf. Bull. Econ. Stat. 65, 655-680.

Munasinghe, M., 1999. Is environmental degradation an inevitable consequence of economic growth: tunneling through the environmental Kuznets curve. Ecol. Econ. 29, 89-109.

Neumayer, E., 2004. Does the "resource curse" hold for growth in genuine income as well? World Dev. 32 , 1627-1640.

Pedroni, P., 1999. Critical values for cointegration tests in heterogeneous panels with multiple regressors. Oxf. Bull. Econ. Stat. 61, 653-670. 
Pedroni, P., 2001a. Purchasing power parity tests in cointegrated panels. Rev. Econ. Stat. 83, 727-731.

Pedroni, P., 2001b. Fully modified OLS for heterogeneous cointegrated panels, in: Baltagi B.H., Fomby, T.B., Hill, R.C. (Eds.), Nonstationary Panels, Panel Cointegration, and Dynamic Panels (Advances in Econometrics, Vol.15). Emerald Group Publishing Limited, United Kingdom, pp. 93-130.

Pedroni, P., 2004. Panel cointegration: Asymptotic and finite sample properties of pooled time series tests with an application to the PPP hypothesis. Econom. Theory 20, 597-625.

Pesaran, H.M., Shin, Y., Smith, R.P., 1999. Pooled mean group estimation of dynamic heterogeneous panels. J. Am. Stat. Assoc. 94, 621-634.

Phillips, P.C.B., Hansen, B.E., 1990. Statistical inference in instrumental variables regression with I(1) processes. Rev. Econ. Stud. 57, 99-125.

Phillips, P.C.B., Moon, H.R., 1999. Linear regression limit theory for nonstationary panel data. Econom. 67, $1057-1112$.

Ranis, G., Stewart, F., Ramirez, A., 2000. Economic growth and human development. World Dev. 28, $197-219$.

Saikkonen, P., 1991. Asymptotically efficient estimation of cointegration regressions. Econom. Theory 7, 1-21.

Shafik, N., 1994. Economic development and environmental quality: an econometric analysis. Oxf. Econ. Pap. 46, 757-773.

Stern, D.I., Common, M.S., 2001. Is there an Environmental Kuznets Curve for sulfur? J. Environ. Econ. Manag. $41,162-178$.

Stern, D.I., Common, M.S., Barbier, E.B., 1996. Economic growth and environmental degradation: the Environmental Kuznets Curve and sustainable development. World Dev. 24, 1151-1160.

Stiglitz, J.E., 2000. Capital market liberalization, economic growth, and instability. World Dev. 28, 1075-1086.

Stock, J.H., Watson, M.W., 1993. A simple estimator of cointegrating vectors in higher order integrated systems. Econom. 61, 783-820.

Suri, T., Boozer, M.A., Ranis, G., Stewart, F., 2011. Paths to success: The relationship between human development and economic growth. World Dev. 39, 506-522.

Tisdell, C., 2001. Globalisation and sustainability: environmental Kuznets curve and the WTO. Ecol. Econ. 39, 185-196.

Vincent, J.R., 1997. Testing for environmental Kuznets curves within a developing countries. Environ. Dev. Econ. 2, 417-431.

World $\quad 2010 . \quad$ Adjusted $\quad$ Net $\quad$ Saving. http://web.worldbank.org/WBSITE/EXTERNAL/TOPICS/ENVIRONMENT/EXTEEI/0,,contentMDK:2050 2388 menuPK:1187778 pagePK:210058 piPK:210062 theSitePK:408050,00.html 